e nsaio $_{\mathbf{n}}$

vol $5 \cdot \mathrm{n}^{\circ} 2 \cdot$ out 2003

\title{
A IMPORTÂNCIA DA REFLEXÃO SOBRE A PRÁTICA DE ENSINO PARA A FORMAÇÃO DOCENTE INICIAL EM CIÊNCIAS BIOLÓGICAS
}

\author{
The Importance of Reflection on Teaching Practice for \\ Pre-Service Biology Teacher Eduction
}

Geilsa Costa Santos Baptista*

\begin{abstract}
RESUMO: Este artigo tem por objetivo demonstrar a importância da reflexão para a formação docente inicial em Ciências Biológicas a partir dos resultados de experiências práticas vivenciadas com alunos pré-formandos do curso de Licenciatura em Ciências Biológicas da Universidade Estadual de Feira de Santana-Bahia e de investigações teóricas sobre ensino e formação docente, desenvolvidos junto ao Núcleo de Estudos e Pesquisas sobre Formação de Professores (NUFOP). Conclui-se que ao oferecer aos licenciandos oportunidades para reflexões e discussões permite-se que estes posicionemse criticamente em relação às suas futuras atividades pedagógicas, desenvolvendo as suas consciências de que ser professor é assumir uma postura pedagógica de investigação e não mais de mero repetidor de conhecimentos.
\end{abstract}

Palavras-chave: Formação docente; Prática de Ensino; Ciências Biológicas.

\begin{abstract}
The goal of this article is to demonstrate the importance of reflection in the preservice biology teacher education based on results of practical experiences with students of the course of Biological Sciences at the State University of Feira de SantanaBahia, as well as on theoretical investigations about teaching and teacher' education, developed at the Nucleus of Studies and Research about Teacher Education (NUFOP). We concluded that as we offer to prospective teachers opportunities to reflect and discuss, we make it possible for them to critically adopt a position in relation to pedagogic activities in the future. Thus, they will develop conscience that being a teacher involves adopting a pedagogic posture of inquiry and not anymore to be merely a knowledge reproducer.
\end{abstract}

Key-word: Teacher education; Teaching Practice; Biological sciences, Teaching Methods courses.

\footnotetext{
* Departamento de Educação - UEFS, Núcleo de Estudos e Pesquisas Sobre a Formação de Professores, UEFS; Grupo de Pesquisa em História, Filosofia e Ensino de Ciências e Biologia, UFBA

e-mail: geilsa@uefs.br
} 


\section{INTRODUÇÃO}

Durante muito tempo da história da educação brasileira o ensino de Ciências, bem como todo o cenário escolar, esteve dominado pelo modelo tradicionalista o qual preocupavase apenas com a transmissão dos conhecimento produzidos pela Ciência ao longo da história da humanidade. Aos alunos cabia a memorização, com base em questionários e livros didáticos, e a repetição dos conteúdos nas provas realizadas, as quais tinham por objetivo central a promoção para séries posteriores. O conhecimento científico era tomado como neutro e não se punha em questão a verdade científica (BRASIL, 1997).

Nessa perspectiva, segundo Monteiro citado por Nunes (2003), ocorria a redução da racionalidade prática à mera racionalidade instrumental, o que obrigava o docente a incorporar as definições externas dos objetivos da sua intervenção, assumindo uma postura passiva diante dos modelos curriculares elaborados por especialistas e dos conteúdos apresentados nos livros didáticos. A formação inicial dos professores era centrada na preparação de profissionais capazes de transmitir conhecimentos já elaborados - e dava profunda ênfase nos conteúdos específicos de sua área de conhecimento, consagrando a separação entre teoria e prática (DOMINGUES, 1998).

Um estudo realizado por Nunes (2003), sobre o histórico do ofício docente no Brasil, revela que somente na década de 1970 foi ficando cada vez mais evidente que a idéia de capacitar o professor com uma linguagem científica e cultural, que assegurasse o conhecimento de um conteúdo a ser ensinado, bem como dotá-lo de alguns componentes psico-pedagógicos, para aprender a atuar em sala de aula, já não oferecia instrumentos teóricos necessários para responder aos desafios do cotidiano escolar. Segundo Rondina (2001), esses desafios envolviam a preocupação com conteúdos das idéias dos estudantes em relação aos diversos conceitos científicos aprendidos na escola.

Segundo Brasil (1998), foi a partir da década de 1980 que o conhecimento escolar deixa de ser entendido como inquestionável passando a ser encarado como um processo. Para Becker citado por Rondina (2001, p. 151) “(...) o aluno passa a ser o centro do processo de ensino-aprendizagem".

Atualmente, a idéia de valorização de pré-concepções científicas está cada vez mais presente nas pesquisas e na literatura em educação (Moreira, 1999; Bizzo, 2001, Melo, 


\section{ensaio}

vol $5 \cdot \mathrm{n}^{\circ} 2 \cdot$ out 2003

2002), que reconhecem que o aprendizado científico não é alheio às questões sócioculturais (BRASIL, 1998). De maneira geral, esses trabalhos têm procurado demonstrar que o aluno estabelece múltiplas relações com o seu meio físico e social e que está interagindo com o meio mais amplo do que o escolar. Isto, certamente exige que o professor não mais assuma uma postura tradicional de ensino, isto é, não mais considere o aluno, do ponto de vista da cognição, como uma "tabula rasa" que vai interagir com objetos do conhecimento somente no contexto da educação escolar (DELIZOICOV, 2002).

Porém, embora muito tenha se mexido no planejamento educacional do pais, na tentativa de que o currículo escolar passe a conceber o aluno como um ser responsável pela construção dos seus conhecimentos, abrindo espaço para que este possa estabelecer relações com o mundo ao seu redor, pode-se afirmar que “(...) há evidências de que, apesar de todas as repulsas verbais, hoje continua-se fazendo nas aulas de ciências praticamente o mesmo que há 60 anos" (Yager e Penick citado por Carvalho e Gil-Pérez, 2003, p. 38), ou seja, os professores continuam tendo impregnada em suas práticas pedagógicas a visão do aluno como um receptor passivo de suas informações prestadas na sala de aula.

Segundo Carvalho e Gil-Pérez (2003), trata-se de uma formação docente que não está submetida a uma crítica explícita, constituindo-se, portanto, em algo "natural", sem questionamento efetivo. Ainda segundo esses autores, para uma crítica fundamentada do ensino habitual e do pensamento docente é preciso: 1) Conhecer as limitações dos habituais currículos enciclopédicos e, ao mesmo tempo, reducionistas (deixando de lado aspectos históricos, sociais etc); 2) Conhecer as limitações da forma habitual de introduzir conhecimentos (esquecer as concepções espontâneas dos alunos, tratamentos puramente operativos etc); 3) Conhecer as limitações dos trabalhos práticos habitualmente propostos (como uma visão deformada do trabalho científico); 4) Conhecer as limitações dos problemas habitualmente propostos (simples exercícios repetitivos); 5) Conhecer as limitações das formas de avaliação habituais (terminais, limitadas e conceituais); 6) Conhecer as limitações das formas de organização escolar habituais, muito distantes das que podem favorecer um trabalho de pesquisa coletivo.

Compreende-se, então, a necessidade de conduzir os futuros professores, na sua formação inicial, a partir das suas próprias concepções, a ampliar seus recursos e modificar suas idéias e atitudes de ensino (CARVALHO, 2003). A formação docente inicial já não pode mais ser reduzida ao estudo e domínio de conteúdos e técnicas para serem utilizadas em suas futuras práticas pedagógicas e até mesmo conduzindo estes a assumir uma 


\section{ensaio}

vol $5 \cdot n^{\circ} 2 \cdot$ out 2003

postura acrítica, como estagiários e meros executores de tarefas solicitadas pelos regentes de estágio supervisionado dentro das universidades ou faculdades.

É, nesse contexto, que Mizukami (2002, p. 167) situa o conceito de reflexão-sobre-a-ação “(...) como um caminho para o aprimoramento da prática e a formação dos professores, por ajudar a refazer o caminho trilhado possibilitando descobrir acertos e erros, e tentar construir novos rumos para a atuação, quando necessário”.

Assim sendo, acreditando na importância da reflexão sobre a ação para que se formem docentes que compreendam a si mesmos e ao mundo à sua volta, levando-os ao questionamento do saber e da experiência (Cerri e Lucca, 2003) é que o objetivo central deste trabalho é demonstrar a importância da reflexão sobre a prática de ensino ${ }^{1}$ para a formação docente inicial a partir dos resultados de experiências práticas vivenciadas com alunos do curso de Licenciatura em Ciências Biológicas da Universidade Estadual de Feira de Santana - Bahia ${ }^{2}$, durante atividades práticas desenvolvidas na disciplina Metodologia e Prática do Ensino de Ciências e Biologia, na qual o Estágio Supervisionado está incluído, bem como de investigações teóricas desenvolvidos junto ao Núcleo de Estudos e Pesquisas sobre a Formação de Professores (NUFOP) sobre e ensino e formação docente em Ciências Biológicas.

Os objetivo dessas atividades teve como referencial uma das propostas de Carvalho e Gil-Pérez acima descritas, ou seja, a de conhecer as limitações da forma habitual de introduzir conhecimentos. Assim, o objetivo das atividades foi centrado em proporcionar ao aluno, futuro docente, a oportunidade para refletir sobre a forma usual do planejamento de ensino partindo da sua observação, análise e discussão.

\section{METODOLOGIA}

As referidas experiências aconteceram através de uma abordagem qualitativa, durante os anos de 2002 e 2003 envolvendo duas turmas, no total de 17 alunos pré-formandos, do curso de Licenciatura em Ciências Biológicas da Universidade Estadual de Feira de Santana. Os procedimentos desenvolvidos para a obtenção dos dados foram os mesmos em ambas as turmas: Inicialmente, foi solicitado a seleção de conteúdos de ensino de Ciências ou de Biologia, a critério dos alunos, partindo das suas experiências individuais e coletivas. Com base na seleção dos conteúdos, foi lançada para os alunos uma questão problema: Qual seria o método mais adequado para o ensino dos conteúdos selecionados? Neste momento, abriu-se espaço para discussão, deixando margem para os alunos explicitarem 


\section{ensaio}

vol $5 \cdot \mathrm{n}^{\circ} 2 \cdot$ out 2003

as suas idéias e concepções, com indicação de um método de ensino.

Tendo selecionado um método, os alunos realizaram análises sobre a abordagem dos conteúdos em diferentes livros didáticos quanto a linguagem, exercícios propostos, ilustrações, contextualização etc. Com base nisso, foi solicitado aos aluno o planejamento de ensino dos conteúdos selecionados.

Por último, a reflexão sobre os planejamentos elaborados que partisse da observação, da análise e da discussão sobre os mesmos. É importante aqui ressaltar que todas as atividades foram desenvolvidas em grupos e que durante as mesmas houve acompanhamento por parte da orientadora (autora), sempre buscando despertar nesses a necessidade de se refletir sobre os diversos saberes que envolvem a docência.

\section{RESULTADOS E DISCUSSÃO}

Os conteúdos selecionados pelos alunos foram diferentes, a saber: Meio Ambiente, pela primeira turma em 2002, e Sistema Solar, pela Segunda turma em 2003. As duas turmas envolvidas indicaram a excursão pedagógica como método que melhor o ensino dos conteúdos que foram selecionados:

"A excursão pedagógica é um excelente caminho que permite ao professor contextualizar ${ }^{3}$ o ensino de Ciências e também de Biologia porque o aluno é levado a ao contato planejado com a natureza e perceber que ela não é apenas um conteúdo do livro didático que o professor utiliza em sala de aula (...)”.

Aqui o aluno demonstra a importância da junção dos objetos de ensino à prática cotidiana dos alunos. Neste contexto Cavalcante (2004), argumenta que uma excursão pedagógica constitui um meio eficiente de estudar Ciências, que envolve o incentivo à investigação, o estímulo ao questionamento e a utilização de recursos além do livro didático e a realização de atividades fora do espaço da sala de aula.

Após análises e discussões sobre os conteúdos selecionados em diferentes livros didáticos, houve consenso por parte dos futuros professores quanto a sua abordagem descontextualizada: "A maioria das citações nos livros didáticos que nós consultamos apresentam os conteúdos com uma linguagem apenas científica, não relacionado-a com contextos e situações para que os aprendizes encontrem significados práticos”. Os alunos declararam que os livros consultados apresentaram diferentes versões para um único fato; os textos não são provocativos e os exercícios não estimulam o raciocínio dos alunos problematizando as questões. 


\section{ensaio}

vol $5 \cdot n^{\circ} 2 \cdot$ out 2003

Partindo das análises dos conteúdos selecionados, os alunos elaboraram planejamentos de ensino, tendo a excursão pedagógica como caminho para alcançar a sua contextualização. De maneira geral, os itens inseridos pelos alunos foram: conteúdos, objetivos, procedimentos, recursos didáticos, avaliação e interdisciplinaridade.

Os locais selecionados para a execução da excursão foram distintos entre as duas turmas, a saber: A primeira turma, a do ano de 2002, indicou o Parque Zoobotânico Getúlio Vargas $^{4}$ como local a ser visitado, localizado em Salvador, capital da Bahia.A justificativa apresentada pelos alunos para a escolha deste local foi que o mesmo consegue abranger amplas características dos elementos naturais.

A Segunda turma, a do ano de 2003, indicou o Observatório Astronômico Antáres ${ }^{5}$, localizado na cidade de Feira de Santana-Bahia, justificando a sua escolha por ser um centro de observações astronômicas e dispor de equipamentos capazes de simular o movimento real dos planetas no sistema solar, supondo despertar a curiosidade dos estudantes para observação.

Considerando o planejamentos de ensino bem como local a ser visitado, os alunos em campo, isto é, nos locais que indicaram para a realização de uma excursão pedagógica, observaram seus planejamentos, analisaram os seus itens criticamente e discutiram a viabilidade de aplicação dos mesmos.

No Parque Zoobotânico Getúlio Vargas, os licenciandos afirmaram que no ensino de Ciências e Biologia, o professor para contextualizar os conteúdos de ensino deverá permitir aos seus alunos o contato com ambientes que lhes sejam próprios, onde estes possam relacionar os conceitos teóricos que são abordados em sala de aula com a realidade que lhes é comum. Isto ficou claro quando um dos licenciandos, ao observar o espaço natural que compreende o Parque Zoobotânico explicitou sua idéia: “(...) podemos trabalhar classificação zoológica, se mostrarmos aos nossos alunos os representantes animais na própria natureza, o que vai lhe ajudar na associação ou não dos conceitos (...)”.

A partir daí foi aberta uma ampla discussão com os discentes sobre contextualização dos conteúdos e sobre os planejamentos por eles elaborados, pois estes perceberam que a realidade em que vão atuar como professores, município de Feira de Santana, pertence não ao ecossistema de Mata Atlântica, no qual está localizado o Parque, mas ao ecossistema de Caatinga. Aqui, ficou evidente que o local escolhido pelos alunos não faz parte da realidade física e nem social da qual irão atuar como professores. Na visão de um aluno:

“A escolha do parque Zoobotânico como local para ministrar uma aula sobre 


\section{ensaio}

vol $5 \cdot \mathrm{n}^{\circ} 2 \cdot$ out 2003

Meio Ambiente Natural não foi acertada, porque o professor que tem sua realidade escolar, e consequentemente dos alunos, inserida na Caatinga não despertaráo interesse e a participação do aluno se discutir sobre as espécies nativas do ecossistema de Mata Atlântica ou de outros ecossistemas que estão representadas aqui no Parque (...)".

No Observatório Astronômico Antares, os alunos consideraram que a visita ao local permite ao professor conduzir os aprendizes a pesquisar informações sobre os planetas: "O Observatório está inserido na nossa comunidade e assim fica fácil trazer o aluno para pesquisar a origem dos nomes dos planetas, seus dados físicos, seus símbolos astronômicos etc". Também consideraram que no planetário, que está localizado dentro do espaço físico do Observatório Astronômico, os aprendizes podem observar o céu e ver a simulação do posicionamento das estrelas no mesmo e conhecer a história da Astronomia.

A partir disso, os alunos repensaram os seus planos e concluíram que é preciso refletir sobre a ação pedagógica pois perceberam que não se pode planejar partindo da cópia de um livro didático, cujo os objetivos nada tenham a ver com o dia-a-dia dos alunos. Na fala de uma aluna:

"No ensino de Ciências Biológicas se faz necessário que o professor defina anteriormente os objetivos, pensando nos interesses e possibilidades dos alunos, o local a ser visitado, que deverá fazer parte da realidade física, social e cultural do aluno, de acordo com as suas expectativas, necessidades e experiências".

\section{CONCLUSÕES}

É fato conhecido que o desenvolvimento profissional dos professores está intimamente relacionado com sua formação. Assim, afirma Delizoicov (2002), as transformações das práticas docentes só se efetivarão se o professor ampliar sua consciência sobre a própria prática, o que pressupõe os conhecimentos teóricos e críticos sobre a realidade.

O desenvolvimento de tal consciência é possível ainda na graduação, durante a vida acadêmica, onde o futuro professor, ao preparar-se para assumir sua função de educador, deverá refletir sobre a prática de ensino.

As experiências vivenciadas, se revelaram estratégia importante, pois ao oferecer aos licenciandos oportunidades para reflexões sobre a prática de ensino, percebeu-se que os mesmos atinaram para a importância da reflexão sobre a própria ação, no caso específico sobre o planejamento de alguns conteúdos de ensino, apontando para a necessidade de 


\title{
$\mathrm{e}_{\mathbf{n}} \mathrm{saio}$
}

$\operatorname{vol} 5 \cdot n^{\circ} 2 \cdot$ out 2003

sua ressignificação. Do mesmo modo, pôde-se refletir sobre a própria prática docente, na formação de professores de Ciências Biológicas, a qual já não pode mais se ater ao modelo da racionalidade técnica.

Assim sendo, conclui-se que preparar o futuro professor para atuar no ensino de Ciências e Biologia na atualidade, requer oferecer-lhe momentos práticos para reflexões sobre esse mesmo ensino, antecedendo a sua atuação enquanto docente, na tomada de consciência de que ser professor é assumir uma postura pedagógica investigação e não mais de mero repetidor de conhecimentos.

\begin{abstract}
${ }^{1}$ Aqui, a expressão Prática de Ensino é definida segundo Ferreira (2003), a qual refere-se tanto ao estágio supervisionado quanto às atividades formativas a ele relacionadas

${ }^{2}$ Segundo o Colegiado de Biologia, o curso de Licenciatura em Ciências Biológicas da Universidade Estadual de Feira de Santana (UEFS) foi implantado em 1986 (Portaria Ministerial № 346 De 03/03/94, DOU 07/03/94). O licenciado em Ciências Biológicas atua predominantemente no ensino básico das escolas públicas estaduais e municipais do município de Feira de Santana, localizado na região semi-árida do estado da Bahia. Este deve ser um profissional capacitado como educador, responsável pelo aperfeiçoamento do processo educativo, do sistema educacional do país e crítico dos processos históricos da evolução da educação visando sempre um ensino ativo e participativo que estimule nos alunos a capacidade de pensar, lógica e criticamente. O currículo do curso - que atualmente encontra-se em transição para um novo currículo que atenda às exigências das atuais normativas legais brasileiras sobre formação de professores - é constituído por disciplinas de Currículo Mínimo (desdobradas das matérias pedagógicas), Complementares Obrigatórias e Complementares Optativas. Entre as disciplinas pedagógicas encontra-se a EDU 254-Metodologia e Prática do Ensino de Ciências e Biologia com 150 horas distribuídas entre 30 horas de teoria, 30 horas de prática e 90 horas de estágio supervisionado. Dentre outros, o objetivo central desta disciplina é analisar de forma crítica e transformadora o ensino de Ciências Biológicas no pais e, do mesmo modo, fornecer subsídio para uma prática docente reflexiva e inovadora.
\end{abstract}

${ }^{3} \mathrm{O}$ conceito de "contextualização do Ensino" trabalhado com os discentes foi de acordo com os Parâmetros Curriculares Nacional para o Ensino Médio (Brasil, 2004) o qual significa dar sentido ao que se aprende. A contextualização retira o aluno da condição de espectador passivo, ao trazer para a escola experiências pessoais, sociais e culturais.

${ }^{4}$ Segundo informações contidas na sua home-page em 05/08/2004, o espaço do Parque Zoobotânico Getúlio Vargas é de aproximadamente $250.000 \mathrm{~m} 2$ e está reservado para a exposição de animais silvestres, para atividades de educação ambiental, e apoio às pesquisas de fauna e flora. O Zôo também é especializado como centro de estudos e exposição de animais da fauna brasileira, uma vez que das 120 espécies atualmente alojadas na Zôo, $80 \%$ destas pertencem à fauna do Brasil. Para maiores informações, consultar: <http://www.girafamania.com.br/introducao/ zoo_salvador.html>

${ }^{5}$ Segundo informações contidas na sua home-page em 05/08/2004, o Observatório Astronômico Antares funciona como um centro de pesquisa, difusão e ensino no campo das ciências astronômicas, astrofísicas, atmosféricas e sensoriamento remoto. Nele, são desenvolvidas atividades com professores e estudantes do ensino Fundamental, Médio e Superior, destacando-se as observações astronômicas ao vivo, aulas, cursos, palestras, projeções de vídeo sobre a história dos programas espaciais, utilização da biblioteca e seções no Planetário. Para maiores informações, consultar: < http://www.uefs.br/antares/> 


\section{REFERÊNCIAS BIBLIOGRÁFICAS}

BIZZO, N. Ciências: fácil ou difícil? 2. Edição. São Paulo: Editora Ática, 2001, 244 p. BRASIL. SEF. MEC. Parâmetros Curriculares Nacionais: Ciências Naturais. Brasilia, 1997, $136 \mathrm{p}$.

$433 \mathrm{p}$

Parâmetros Curriculares para o Ensino Fundamental. Brasília, 1998,

O que é o Ensino Médio?. Arquivo capturado [online] via Internet em 05.08.2004, no endereço eletrônico: http://www.mec.gov.br/semtec/ensmed/ intromedio.shtm

CARVALHO, A M. P. de. A Inter-relação entre a Didática das Ciências e a Prática de Ensino. In: SALES, S. E. \& FERREIRA, M. S. Formação Docente em Ciências: Memórias e Práticas. Niterói: Eduff, 2003, 117-135 p.

CARVALHO, A. M. P. de e GIL-PÉREZ, D. Formação de Professores de Ciências. São Paulo: Cortez, 2003, $120 \mathrm{p}$.

CAVAlCANTE, M. Meio Ambiente: de Perto é bem mais fácil. In: Revista Nova Escola, Ano XIX, Número 169, janeiro/fevereiro de 2004, 46-49 p.

CERRI, Y. L. N. S. \& LUCCA, D. A Importância do Processo reflexivo na Formação Inicial de Professores de Ciências. In: Anais do I EREBIO: Novo Milênio, Novas Práticas Educacionais? Niterói: Universidade Federal Fluminense, 2003, 204-207 p.

DELIZOICOV, D. e outros. Ensino de Ciências: Fundamentos e Métodos. São Paulo: Cortez, $2002,365 \mathrm{p}$.

DOMINGUES, J. L. Anotações de Leitura dos Parâmetros Nacionais do Currículo de Ciências. In: Os Currículos do Ensino Fundamental Para as Escolas Públicas Brasileiras. São Paulo: Autores Associados, 1998, 193-200 p.

FERREIRA, S. M. Formação Docente em Ciências Biológicas. Estabelecendo Relações Entre Prática de Ensino e o Contexto Escolar. In: SALES, S. E. \& FERREIRA, M. S. Formação Docente em Ciências: Memórias e Práticas. Niterói: Eduff, 2003, 29-46 p.

MELO, M. do R. de. Ensino de Ciências: uma participação ativa e cotidiana. Arquivo capturado [online] via Internet em 21.03.2002, no endereço eletrônico: < http:// www.rosamelo.com.br>.

MIRANDA, I. A Programas de Interação entre a Educação Formal e a Não Formal no MAST. In: Anais do I EREBIO, Niterói: Universidade Federal Fluminense, 2001, p. 313 - $316 \mathrm{p}$.

MIZUKAMI, M. da G. N. e outros. Escola e Aprendizagem da Docência: processos da Investigação e Formação. São Carlos: EdUFSCar, 2002, 203 p.

MOREIRA, M. A Aprendizagem Significativa. Brasilia: Editora UnB, 1999, 129 p.

NUNES, C. Memórias e Práticas na Construção Docente. In: SALES, S. E. \& FERREIRA, M. S. Formação Docente em Ciências: Memórias e Práticas. Niterói: Eduff, 2003, 11-27

RONDINA, R. de C. A Difusão do Construtivismo no Ensino Fundamental: relato de uma Pesquisa. In: Cadernos de Educação, Vol. 5, Número 01, Cuiabá: EdUNIC, 2001, p. 145181 